\title{
Kontenplan der Nordbank AG
}

\section{Klasse 1}

10 Kasse

11 Bundesbank

12 Eigene Wertpapiere

\section{Klasse 2}

20 Banken-KK

21 Kunden-KK

22 Spareinlagen

23 Termineinlagen

24 Begebene Schuldverschreibungen

\section{Klasse 3}

30 Betriebs- und Geschäftsausstattung

31 Grundstücke und Gebäude

32 Sammelposten (GWG)

33 Geringwertige Wirtschaftsgüter (GWG)

\section{Klasse 4}

40 Umsatzsteuer

41 Vorsteuer

\section{Klasse 5}

50 Zinserträge aus Kreditgeschäften

51 Zinserträge aus Wertpapieren

52 Provisionserträge

53 Kursgewinne aus Wertpapieren

54 Erträge aus Zuschreibungen zu Wertpapieren

55 Erträge aus Zuschreibungen zu Forderungen

56 Sonstige betriebliche Erträge

\section{Klasse 6}

60 Zinsaufwendungen

61 Provisionsaufwendungen

62 Kursverluste aus Wertpapieren

63 Andere Verwaltungsaufwendungen

64 Einstellungen in den Fonds für allgemeine Bankrisiken

65 Kostensteuern

66 Abschreibungen auf Sachanlagen

67 Abschreibungen auf Wertpapiere

68 Abschreibungen auf Forderungen

69 Sonstige betriebliche Aufwendungen

\section{Klasse 7}

70 Gezeichnetes Kapital

71 Kapitalrücklage

72 Gesetzliche Gewinnrücklagen

73 Andere Gewinnrücklagen

74 Rückstellungen

75 Einzelwertberichtigungen auf Forderungen

76 Pauschalwertberichtigungen auf Forderungen

77 Fonds für allgemeine Bankrisiken

78 Gewinn- und Verlustkonto

79 Bilanzgewinn/-verlust 